\title{
Manejo de plantas daninhas em cana-de-açúcar (Saccharum spp.) cultivada com a operação de quebra-lombo visando à colheita mecanizada
}

\author{
Weed management in sugarcane (Saccharum spp.) grown with break-backs \\ operation aiming mechanized harvesting
}

Fernando Tadeu de Carvalho ${ }^{1 *}$; Talita Breda Moretti ${ }^{2}$

\begin{abstract}
Resumo - A colheita mecanizada introduziu alguns fatores novos no cultivo da cana-de-açúcar que afetaram a dinâmica de ocorrência e o controle das plantas daninhas. Um desses fatores é a operação de quebra-lombo realizada entre 60 a 90 dias após o plantio (DAP) visando uniformizar o terreno para o trabalho da máquina colhedora, entretanto, esta operação causa uma redução no período residual dos herbicidas aplicados no plantio. O presente trabalho foi desenvolvido com o objetivo de avaliar a seletividade e a eficácia do controle químico de plantas daninhas aplicado em duas épocas: no plantio da cultura e após a operação de quebra-lombo. O experimento foi desenvolvido no período de novembro de 2008 a junho de 2009, em área de cultivo da Usina Vale do Paraná, SP, em cana-planta variedade RB 92579, com espaçamento de 1,5 m entrelinhas. A operação de quebra-lombo foi realizada aos 70 DAP. O delineamento experimental utilizado foi o de blocos ao acaso, com oito tratamentos e quatro repetições. As aplicações foram realizadas em pré-emergência (no plantio) e em pós-emergência da cultura (após o quebralombo), utilizando-se um pulverizador pressurizado $\left(\mathrm{CO}_{2}\right)$, com barra equipada com quatro pontas do tipo leque, espaçadas de $0,5 \mathrm{~m}$ e volume de calda de $200 \mathrm{~L} \mathrm{ha}^{-1}$. Observou-se que o tratamento s-metolachlor (1920 $\mathrm{g} \mathrm{ha}^{-1}$, no plantio) e s-metolachlor + ametryn $\left(1920+1500 \mathrm{~g} \mathrm{ha}^{-1}\right.$, após o quebra-lombo) foi eficiente no controle de Brachiaria decumbens e Mimosa pudica, e foi seletivo às plantas de cana-de-açúcar. O tratamento s-metolachlor (1920 $\mathrm{g} \mathrm{ha}^{-1}$, no plantio) e smetolachlor + hexazinone+diuron $\left(1920+900 \mathrm{~g} \mathrm{ha}^{-1}\right.$, após o quebra-lombo $)$ foi eficiente no controle de $B$. decumbens e foi seletivo às plantas de cana-de-açúcar. O tratamento s-metolachlor (1920 $\mathrm{g} \mathrm{ha}^{-1}$, no plantio) e s-metolachlor + amicarbazone $\left(1920+1050 \mathrm{~g} \mathrm{ha}^{-1}\right.$, após o quebralombo) foi altamente eficiente no controle de B. decumbens e $M$. pudica, mas foi pouco seletivo às plantas de cana-de-açúcar. $O$ tratamento s-metolachlor + ametryn $\left(960+750 \mathrm{~g} \mathrm{ha}^{-1}\right.$, no plantio) e s-metolachlor + ametryn $\left(960+1500 \mathrm{~g} \mathrm{ha}^{-1}\right.$, após o quebra-lombo) foi eficiente no controle de $M$. pudica e foi seletivo às plantas da cultura.
\end{abstract}

Palavras-chave: Cana-crua, s-metolachlor, ametryn, hexazinone-diuron, amicarbazone.

Abstract - Mechanized harvesting has introduced some new factors in the cultivation of sugar cane which affect the dynamics of occurrence and weed control. One such factor is the operation of break-backs performed 60 to 90 days after planting in order to standardize the soil to work the machine harvester, but this operation causes damages to residual herbicides applied at planting. The present work was to evaluate the selectivity and performance of chemical weed control

\footnotetext{
$1_{*}$ Professor Dr., DBZ-FEIS-UNESP, Ilha Solteira/SP, Brasil. E-mail: ftadeu@ bio.feis.unesp.br

${ }^{2}$ Pós-graduanda de Agronomia, FEIS-UNESP, Ilha Solteira/SP.
} 
applied in two seasons: the planting of the crop and after the operation of break-backs. The experiment was carried out from November 2008 to June 2009, in the growing area of Vale do Parana distillery, Brazil, in plant-cane variety RB 92579, spaced $1.5 \mathrm{~m}$ between rows. The operation of break- backs was performed 70 days after planting. The experimental design was randomized blocks with 8 treatments and 4 replicates. The applications were performed in preemergence (at planting) and post-emergence of crop (after the break-backs), using a pressurized sprayer $\left(\mathrm{CO}_{2}\right)$, with a bar equipped with four nozzles of the fan type, spaced at $0.5 \mathrm{~m}$ and a volume of $200 \mathrm{~L} \mathrm{ha}^{-1}$. It was observed that treatment s-metolachlor $\left(1920 \mathrm{~g} \mathrm{ha}^{-1}\right.$ at planting $)$ and s-metolachlor + ametryn $\left(1920+1500 \mathrm{~g} \mathrm{ha}^{-1}\right.$ after the break-backs $)$ was effective in control of Brachiaria decumbens and Mimosa pudica, and was selective to plants of sugar cane. The treatment s-metolachlor (1920 $\mathrm{g} \mathrm{ha}^{-1}$ at planting) and s-metolachlor + hexazinone+diuron $(1920+$ $900 \mathrm{~g} \mathrm{ha}^{-1}$, after the break-backs) was effective in controlling $B$. decumbens and was selective to plants of sugar cane. The treatment s-metolachlor (1920 $\mathrm{g} \mathrm{ha}^{-1}$ at planting) and s-metolachlor + amicarbazone $\left(1920+1050 \mathrm{~g} \mathrm{ha}^{-1}\right.$, after the break-backs) was highly efficient in controlling $B$. decumbens and $M$. pudica, but had little selectivity to plant sugar cane. The treatment smetolachlor + ametryn $\left(960+750 \mathrm{~g} \mathrm{ha}^{-1}\right.$ at planting $)$ and s-metolachlor + ametryn $(960+1500 \mathrm{~g}$ $\mathrm{ha}^{-1}$ after the break-backs) was effective in controlling $M$. pudica and was selective to the crop.

Key-words: Raw-cane, s-metolachlor, ametryn, hexazinone-diuron, amicarbazone.

\section{Introdução}

O preparo do solo para o plantio da canade-açúcar é realizado com implementos capazes de proporcionar um sulcamento considerado profundo, em torno de $30 \mathrm{~cm}$, se comparado com o de outras culturas como o milho e a soja. Segundo Silveira (1989) a abertura de sulcos rasos para o plantio ou semeadura de culturas anuais é chamada de riscação, e os sulcos profundos para o plantio de culturas semi-perenes, como a cana-deaçúcar, é chamada de sulcação. O plantio da cana-de-açúcar em sulcos profundos é importante para a boa fixação das plantas no solo e para evitar o acamamento futuro, garantindo vários cortes da cultura, nos anos consecutivos.

Apesar da profundidade dos sulcos, a quantidade de terra utilizada para recobrir os colmos de cana-de-açúcar é pequena, de maneira a evitar o abafamento dos colmos, mas o suficiente para o bom pegamento das gemas. Desta forma, estas características do plantio: sulcos profundos e com pouco recobrimento de terra, proporcionam superfícies bastante irregulares no terreno (Carvalho, 1999).

Atualmente, com a introdução da colheita mecanizada na cana-de-açúcar, tornou-se necessário algumas adequações na condução da lavoura. Uma delas é a utilização de espaçamentos mais amplos, em torno de $1,50 \mathrm{~m}$, e outra é a operação de quebra-lombo realizada após a emergência da cultura, por volta dos 60 a 70 DAP, visando uniformizar o terreno para que a máquina colhedora possa trabalhar regularmente. Entretanto esta tecnologia causou mudanças no sistema de cultivo da cana-de-açúcar e, como conseqüência, na ocorrência e manejo das plantas daninhas.

Pitelli \& Kuva (1998) já previam que a cultura da cana-de-açúcar passaria por um grande processo de mudança no seu sistema produtivo, em razão da adoção da colheita mecanizada sem queima prévia da palha. Segundo os autores, as mudanças no sistema de produção agrícola sempre acarretam alterações ambientais que resultam em grande impacto na 
população de plantas daninhas, pois atuam como fator ecológico não-periódico.

Como a grande maioria dos herbicidas utilizados em cana-de-açúcar são préemergentes (Rodrigues \& Almeida, 2005) a questão principal passou a ser como manejar as plantas daninhas tendo uma operação de quebra-lombo dentro do período em que o herbicida atua de forma residual.

A técnica de se fazer uma única aplicação após o plantio da cultura, pode não ser mais eficiente porque a operação de quebra-lombo, ao remover o solo, danifica o residual do herbicida (Christoffoleti, 2009). Além disso, ainda existe a questão do espaçamento mais amplo que demanda um maior período de tempo para o fechamento da cultura, favorecendo a ocorrência de plantas daninhas.

Uma opção que já vem sendo realizada em algumas usinas é a utilização de duas aplicações, sendo a primeira na época do plantio, com herbicidas mais baratos, e a segunda após a operação de quebra-lombo, com herbicidas mais eficazes para as espécies daninhas que ocorrem na região. Ou seja, a primeira aplicação visando mais o custo e a segunda visando mais a eficácia. Neste aspecto, o que tem sido requerido são informações sobre quais são as melhores opções em eficácia entre os herbicidas mais baratos para serem utilizados na primeira aplicação.

Entre os herbicidas que tem sido utilizado, o trifluralin tem o espectro de controle relativamente baixo, sendo eficaz somente para as gramíneas e precisa ser incorporado ao solo e, o pendimethalin também tem o espectro de controle baixo e necessita de incorporação (Rodrigues \& Almeida, 2005).

Entre as opções atuais, o s-metholachlor é um herbicida seletivo para a cana-de-açúcar indicado para o controle pré-emergente de plantas daninhas com ação acentuada sobre gramíneas e algumas dicotiledôneas (Rodrigues
\& Almeida, 2005). Por se enquadrar na relação de herbicidas mais baratos e por sua boa eficácia no controle das plantas daninhas, a utilização do s-metholachlor pode ser uma boa opção para ser usado na primeira aplicação, ou seja, visando o manejo das infestantes até o quebra-lombo.

As mudanças proporcionadas pela colheita mecanizada da cana-de-açúcar trouxeram várias questões que ainda necessitam de respostas e por isso, é importante que as pesquisas sejam regionalizadas, devido às diferenças nos tipos de solos e clima e das espécies daninhas que ocorrem. Desta forma, o presente trabalho foi desenvolvido com o objetivo de avaliar a seletividade e a performance do controle químico de plantas daninhas aplicado em duas épocas: no plantio da cultura e após o quebra-lombo.

\section{Material e métodos}

O trabalho foi desenvolvido no período de novembro/2008 a junho/2009, em área de cultivo da Usina Vale do Paraná, nas coordenadas de $20^{\circ} 27^{\prime} 40,9^{\prime \prime}$ de latitude sul e $51^{\circ} 01^{\prime} 02,3$ " de longitude oeste, com 345 metros de altitude, no município de Suzanápolis, na região noroeste do Estado de São Paulo.

O solo da área experimental é classificado como Latossolo Vermelho, textura média-arenosa, com $26 \%$ de argila, $66 \%$ de areia e $8 \%$ de silte. O experimento foi conduzido em área de cana-planta, variedade RB 92-579, plantada em 26/11/2008, com espaçamento de $1,5 \mathrm{~m}$ entrelinhas. Os tratos culturais realizados na área, no que diz respeito às adubações e ao controle de pragas, foram os normais exigidos pela cultura e realizados na área de cultivo. A operação de quebra-lombo foi realizada manualmente aos 70 DAP (Figura $1)$. 


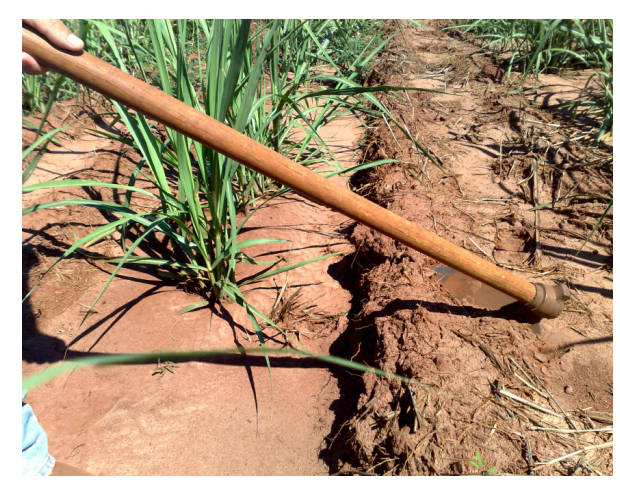

Operação manual de quebra-lombo.

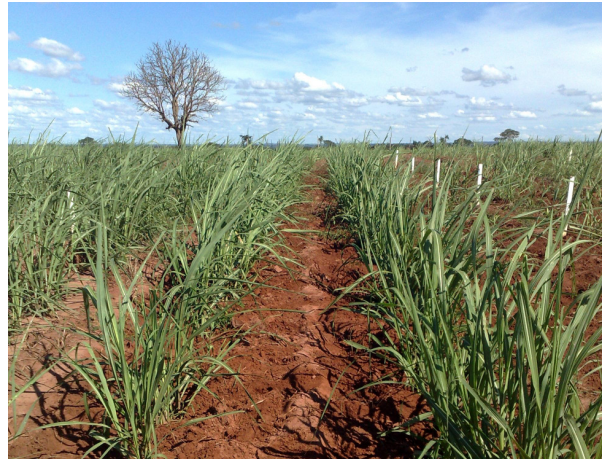

Detalhe da entre linha após o quebra-lombo.

Figura 1. Entre linha da cana-de-açúcar antes e após a operação de quebra-lombo.

Tabela 1. Condições edafoclimáticas nas aplicações. Suzanapólis/SP (2008/09).

\begin{tabular}{ccccccc}
\hline Aplicação & Data & Horário & Solo & Tp. ar & UR ar & Vento \\
\hline $1^{\mathrm{A}}$ (no plantio) & $28 / 11 / 08$ & $20: 00-20: 30$ & $\mathrm{c} /$ umidade & $27^{\circ} \mathrm{C}$ & $68 \%$ & $<2 \mathrm{~km} / \mathrm{h}$ \\
\hline $2^{\mathrm{A}}$ (no quebra-lombo) & $04 / 02 / 09$ & $19: 00-19: 30$ & $\mathrm{c} /$ umidade & $30^{\circ} \mathrm{C}$ & $60 \%$ & $<2 \mathrm{~km} / \mathrm{h}$ \\
\hline
\end{tabular}

$\mathrm{O}$ delineamento experimental utilizado pressurizado $\left(\mathrm{CO}_{2}\right.$ a $\left.40 \mathrm{lb} \mathrm{pol}{ }^{-2}\right)$, provido de foi o de blocos ao acaso, com oito tratamentos tanque com capacidade de dois litros (garrafas (Tabela 2) e quatro repetições. Cada parcela descartáveis) e barra equipada com quatro constou de quatro linhas da cultura com $5 \mathrm{~m}$ de pontas do tipo leque, marca Teejet XR110.03, comprimento e $6 \mathrm{~m}$ de largura, totalizando 30 espaçadas de $0,5 \mathrm{~m}$. O volume de calda $\mathrm{m}^{2}$.

As aplicações dos herbicidas foram aplicado foi de $200 \mathrm{~L} \mathrm{ha}^{-1}$. realizadas com um pulverizador costal

Tabela 2. Tratamentos utilizados no experimento. Suzanapólis/SP (2008/09).

\begin{tabular}{|c|c|c|}
\hline Tratamentos & Dose (g i.a. ha $\left.{ }^{-1}\right)$ & Época de Aplicação \\
\hline 1- testemunha no mato & -- & -- \\
\hline 2- testemunha no limpo & -- & -- \\
\hline 3- s-metolachlor & 1920 & no plantio \\
\hline s-metolachlor + ametryn $^{2}$ & $1920+750$ & no quebra-lombo \\
\hline 4- s-metolachlor & 1920 & no plantio \\
\hline s-metolachlor + ametryn & $1920+1500$ & no quebra-lombo \\
\hline 5- s-metolachlor & 1920 & no plantio \\
\hline s-metolachlor + hexazinone+diuron ${ }^{3}$ & $1920+900$ & no quebra-lombo \\
\hline 6- s-metolachlor & 1920 & no plantio \\
\hline s-metolachlor + amicarbazone ${ }^{4}$ & $1920+1050$ & no quebra-lombo \\
\hline 7- s-metolachlor + ametryn & $960+750$ & no plantio \\
\hline s-metolachlor + ametryn & $960+750$ & no quebra-lombo \\
\hline 8- s-metolachlor + ametryn & $960+750$ & no plantio \\
\hline s-metolachlor + ametryn & $960+1500$ & no quebra-lombo \\
\hline
\end{tabular}


Os tratamentos foram aplicados em préemergência da cultura aos dois DAP e em pósemergência da cultura logo após a operação de quebra-lombo aos 70 DAP. No momento das aplicações (no plantio e após o quebra-lombo) o solo encontrava-se com umidade e praticamente não ventava; a temperatura do ambiente foi menor que $30^{\circ} \mathrm{C}$ e UR do ar superior a $60 \%$. As condições climáticas no momento das aplicações estão descritas na Tabela 1 .

A eficácia dos tratamentos no controle das plantas daninhas foi avaliada antes da operação de quebra-lombo aos 60 dias após a primeira aplicação e aos 15, 30, 60, 90 e 120 dias após a segunda aplicação, quando houve o fechamento da cultura. Utilizou-se uma escala visual, onde $0 \%$ representou nenhum controle e $100 \%$ o controle total das plantas daninhas. Considerou-se como eficaz o controle igual ou superior a $80 \%$, conforme metodologia proposta por SBCPD (1995).

A seletividade dos tratamentos às plantas da cultura foi avaliada visualmente considerando-se a biomassa e a coloração das plantas tratadas comparadas com as plantas da testemunha e atribuindo-se notas de $0 \%$ a $100 \%$, onde $0 \%$ representou nenhum sintoma de fitointoxicação e $100 \%$ a morte total das plantas. A avaliação de crescimento da cultura (biometria) em cada parcela foi realizada aos 210 dias após o plantio (7 meses), sendo as seguintes: diâmetro do colmo (avaliado no $2^{\underline{0}}$ entre-nó), altura média de 10 plantas (avaliada na altura do último entre-nó) e número de perfilhos (contados em dois metros úteis).

\section{Resultados e discussão}

As espécies daninhas que ocorreram no experimento foram a Brachiaria decumbens (capim-braquiária) e a Mimosa pudica (sensitiva). A infestação média de plantas daninhas na área experimental antes do quebra- lombo (aos 70 DAP) foi de $22 \%$ e $36 \%$ e após o quebra-lombo (aos 120 dias) foi de $55 \%$ e $42 \%$, respectivamente, para $B$. decumbens e $M$. pudica. Ressalta-se que houve uma redução da infestação na primeira avaliação após o quebralombo. As plantas daninhas remanescentes foram as que ficaram na linha da cana-deaçúcar. A partir daí iniciou-se a reinfestação nas parcelas não tratadas o que demonstrou que a operação de quebra-lombo por si só não foi suficiente para o controle das plantas daninhas.

A situação da área experimental antes da operação de quebra-lombo representava a eficácia dos herbicidas antes da segunda aplicação. Observou-se que os tratamentos com s-metolachlor na dose de 1920 g/ha proporcionaram controle superior a $91 \%$ para a espécie $B$. decumbens, enquanto que smetolachlor + ametryn $\left(960+750 \mathrm{~g} \mathrm{ha}^{-1}\right)$ foi menos eficaz proporcionando controle de $80 \%$, aos 70 DAP. Esse resultado era esperado devido à redução na dose do s-metolachlor e à baixa eficácia do ametryn para $B$. decumbens quando aplicado em pré-emergência (Lorenzi, 2006). Para a espécie $M$. pudica os tratamentos proporcionaram controle inferior a $80 \%$, aos 70 DAP.

Os dados de porcentagem de controle das plantas daninhas após a segunda aplicação estão apresentados nas Tabelas 3 e 4. Considerando a avaliação realizada aos 120 dias após o quebra-lombo, observou-se que, para a espécie $B$. decumbens foram eficientes os tratamentos s-metolachlor (1920 $\mathrm{g} \mathrm{ha}^{-1}$, no plantio $)+$ s-metolachlor+ametryn $(1920+$ $1500 \mathrm{~g}$ ha $^{-1}$, após o quebra-lombo), proporcionando controle de 82,5\%; o tratamento s-metolachlor $\left(1920 \mathrm{~g} \mathrm{ha}^{-1}\right.$, no plantio) + s-metolachlor+hexazinone+diuron $\left(1920+900 \mathrm{~g} \mathrm{ha}^{-1}\right.$, após o quebra-lombo), proporcionando controle de $83,8 \%$ e o tratamento s-metolachlor $\left(1920 \mathrm{~g} \mathrm{ha}^{-1}\right.$, no plantio) + s-metolachlor+ amicarbazone (1920 $+1050 \mathrm{~g} \mathrm{ha}^{-1}$, após o quebra-lombo), proporcionando controle de $94,0 \%$. 
Tabela 3. Eficácia no controle de capim-braquiária. Suzanapólis/SP (2008/09).

\begin{tabular}{|c|c|c|c|c|c|c|}
\hline \multirow[b]{2}{*}{ TRATAMENTOS } & \multirow[b]{2}{*}{$\begin{array}{l}\text { DOSE } \\
\text { (g/ha) }\end{array}$} & \multicolumn{5}{|c|}{$\%$ de Controle de Brachiaria decumbens } \\
\hline & & $\begin{array}{c}15 \\
\text { DAQL }\end{array}$ & $\begin{array}{c}30 \\
\text { DAQL }\end{array}$ & $\begin{array}{c}60 \\
\text { DAQL }\end{array}$ & $\begin{array}{c}90 \\
\text { DAQL }\end{array}$ & $\begin{array}{c}120 \\
\text { DAQL }\end{array}$ \\
\hline 1- Testemunha no mato & -- & 0,0 & 0,0 & 0,0 & 0,0 & 0,0 \\
\hline 2- Testemunha no limpo & -- & 100,0 & 100,0 & 100,0 & 100,0 & 100,0 \\
\hline $\begin{array}{l}\text { 3- s-metolachlor (no plantio) } \\
\text { 3- s-metolachlor + ametryn (anós OL) }\end{array}$ & $\begin{array}{c}1920 \\
1920+750\end{array}$ & 97.0 & 95.0 & 86.0 & 80.0 & 72.5 \\
\hline $\begin{array}{l}\text { 4- s-metolachlor (no plantio) } \\
4 \text { s-metolachlor + ametryn (após QL) }\end{array}$ & $\begin{array}{c}1920 \\
1920+1500 \\
\end{array}$ & 97,3 & 96,0 & 92,8 & 86,5 & 82,5 \\
\hline $\begin{array}{l}\text { 5- s-metolachlor (no plantio) } \\
\text { 5- s-metolachlor + hexazinone+diuron (após QL) }\end{array}$ & $\begin{array}{c}1920 \\
1920+900\end{array}$ & 98,0 & 96,0 & 92,5 & 85,0 & 83,8 \\
\hline $\begin{array}{l}\text { 6- s-metolachlor (no plantio) } \\
\text { 6- s-metolachlor + amicarbazone (após QL) }\end{array}$ & $\begin{array}{c}1920 \\
1920+1050\end{array}$ & 98,5 & 98,0 & 95,5 & 94,3 & 94,0 \\
\hline $\begin{array}{l}\text { 7- s-metolachlor + ametryn (no plantio) } \\
\text { 7- s-metolachlor + ametryn (após QL) }\end{array}$ & \begin{tabular}{|l|}
$960+750$ \\
$960+750$ \\
\end{tabular} & 94,5 & 93,0 & 67,5 & 58,8 & 52,5 \\
\hline $\begin{array}{l}\text { 8- s-metolachlor + ametryn (no plantio) } \\
\text { 8- s-metolachlor + ametryn (após QL) }\end{array}$ & $\begin{array}{c}960+750 \\
960+1500\end{array}$ & 95,5 & 93,5 & 88,0 & 65,0 & 55,0 \\
\hline
\end{tabular}

QL = Quebra-lombo; DAQL = Dias após o Quebra-lombo.

Tabela 4. Eficácia no controle de sensitiva. Suzanapólis/SP (2008/09).

\begin{tabular}{|c|c|c|c|c|c|c|}
\hline \multirow[b]{2}{*}{ TRATAMENTOS } & \multirow[b]{2}{*}{$\begin{array}{l}\text { DOSE } \\
\text { (g/ha) }\end{array}$} & \multicolumn{5}{|c|}{$\%$ de Controle de Mimosa pudica } \\
\hline & & $\begin{array}{c}15 \\
\text { DAQL }\end{array}$ & $\begin{array}{c}30 \\
\text { DAQL }\end{array}$ & $\begin{array}{c}60 \\
\text { DAQL }\end{array}$ & $\begin{array}{c}90 \\
\text { DAQL }\end{array}$ & $\begin{array}{c}120 \\
\text { DAQL }\end{array}$ \\
\hline 1- Testemunha no mato & -- & 0,0 & 0,0 & 0,0 & 0,0 & 0,0 \\
\hline 2- Testemunha no limpo & -- & 100,0 & 100,0 & 100,0 & 100,0 & 100,0 \\
\hline $\begin{array}{l}\text { 3- s-metolachlor (no plantio) } \\
\text { 3- s-metolachlor + ametryn (após QL) }\end{array}$ & $\begin{array}{c}1920 \\
1920+750\end{array}$ & 96,5 & 91,8 & 87,5 & 72,5 & 70,0 \\
\hline $\begin{array}{l}\text { 4- s-metolachlor (no plantio) } \\
4 \text { s-metolachlor + ametryn (após QL) }\end{array}$ & $\begin{array}{c}1920 \\
1920+1500\end{array}$ & 97,8 & 94,8 & 92,3 & 88,0 & 83,0 \\
\hline $\begin{array}{l}\text { 5- s-metolachlor (no plantio) } \\
\text { 5- s-metolachlor + hexazinone+diuron (após QL) }\end{array}$ & $\begin{array}{c}1920 \\
1920+900\end{array}$ & 94,5 & 93,5 & 89,3 & 80,0 & 74,0 \\
\hline $\begin{array}{l}\text { 6- s-metolachlor (no plantio) } \\
\text { 6- s-metolachlor + amicarbazone (após QL) }\end{array}$ & $\begin{array}{c}1920 \\
1920+1050\end{array}$ & 98,5 & 98,5 & 97,3 & 97,0 & 97,0 \\
\hline $\begin{array}{l}\text { 7- s-metolachlor + ametryn (no plantio) } \\
\text { 7- s-metolachlor + ametryn (após QL) }\end{array}$ & $\begin{array}{l}960+750 \\
960+750 \\
\end{array}$ & 92,0 & 77,5 & 72,5 & 62,5 & 44,0 \\
\hline $\begin{array}{l}\text { 8- s-metolachlor + ametryn (no plantio) } \\
\text { 8- s-metolachlor + ametryn (após QL) }\end{array}$ & $\begin{array}{c}960+750 \\
960+1500\end{array}$ & 96,8 & 95,5 & 92,5 & 90,0 & 85,0 \\
\hline
\end{tabular}

$\mathrm{QL}=$ Quebra-lombo; DAQL = Dias após o Quebra-lombo.

Quanto à seletividade observou-se que quando os herbicidas foram aplicados em préemergência da cultura os sintomas de fitointoxicação às plantas de cana-de-açúcar foram bastante baixos, menores que 3,0\%, aos 30 DAP.

Para a aplicação realizada após o quebralombo, em pós-emergência da cultura, os sintomas foram mais pronunciados. Observouse que todos os tratamentos proporcionaram sintomas de fitointoxicação inicial que foram reduzindo nas avaliações subsequentes. O tratamento com o herbicida amicarbazone proporcionou sintomas de fitointoxicação superiores aos demais tratamentos. Os dados de biometria estão apresentados na Tabela 3. No caso da testemunha no mato a redução no porte 
da cultura foi decorrente interferência imposta $\mathrm{ha}^{-1}$, no plantio), observou-se uma redução na pelas plantas daninhas. No tratamento s- altura da cultura em decorrência da baixa metolachlor+ametryn $\left(920+750 \mathrm{~g} \mathrm{ha}^{-1}\right.$, no eficácia no controle das plantas daninhas. plantio $)+$ s-metolachlor+ametryn $(920+750 \mathrm{~g}$

Tabela 3. Dados de crescimento da cultura, aos 210 DAP. Suzanapólis/SP (2008/09).

\begin{tabular}{|c|c|c|c|c|}
\hline TRATAMENTOS & $\begin{array}{l}\text { Dose } \\
\text { (g i.a./ ha) }\end{array}$ & $\begin{array}{l}\text { Diâmetro } \\
(\mathrm{mm})\end{array}$ & $\begin{array}{l}\text { Altura } \\
(\mathrm{cm})\end{array}$ & $\begin{array}{l}\mathrm{N}^{\mathrm{o}} \text { perfilhos } \\
\text { por metro }\end{array}$ \\
\hline 1- Testemunha no mato & -- & $28,3 \quad b$ & $143,6 \mathrm{c}$ & $6,6 \quad b$ \\
\hline 2- Testemunha no limpo & -- & 30,9 & 168,1 & 11,0 \\
\hline $\begin{array}{l}\text { 3- s-metolachlor (no plantio) } \\
\text { s-metolachlor + ametryn (após QL) }\end{array}$ & $\begin{array}{c}1920 \\
1920+750\end{array}$ & 30,5 & 161,5 & 10,9 \\
\hline $\begin{array}{l}\text { 4- s-metolachlor (no plantio) } \\
\text { s-metolachlor + ametryn (após QL) }\end{array}$ & $\begin{array}{c}1920 \\
1920+1500\end{array}$ & 30,7 & 166,0 & 11,0 \\
\hline $\begin{array}{l}\text { 5- s-metolachlor (no plantio) } \\
\text { s-metolachlor + hexazinone+diuron (após QL) }\end{array}$ & $\begin{array}{c}1920 \\
1920+900 \\
\end{array}$ & 30,6 & 161,3 & 11,0 \\
\hline $\begin{array}{l}\text { 6- s-metolachlor (no plantio) } \\
\text { s-metolachlor + amicarbazone (após QL) }\end{array}$ & $\begin{array}{c}1920 \\
1920+1050\end{array}$ & 28,2 & 145,5 & 10,1 \\
\hline $\begin{array}{l}\text { 7- s-metolachlor + ametryn (no plantio) } \\
\text { s-metolachlor + ametryn (após QL) }\end{array}$ & $\begin{array}{l}960+750 \\
960+750 \\
\end{array}$ & 30,3 & 157,7 & 10,6 \\
\hline $\begin{array}{l}\text { 8- s-metolachlor + ametryn (no plantio) } \\
\text { s-metolachlor + ametryn (após QL) }\end{array}$ & $\begin{array}{c}960+750 \\
960+1500\end{array}$ & 30,3 & 159,3 & 10,5 \\
\hline Média Geral (4 repetições) & & 29,94 & 157,86 & 10,22 \\
\hline Teste f (tratamentos) & & $7,77 * *$ & $10,96 * *$ & $6,71 * *$ \\
\hline Coeficiente de Variação & & $2,59 \%$ & $3,41 \%$ & 11,22 \\
\hline DMS $(5 \%)$ & & 1,84 & 12,76 & 2,72 \\
\hline
\end{tabular}

i.a. ha $^{-1}=$ ingrediente ativo por hectare; - médias seguidas por letras iguais nas colunas não diferem entre si pelo teste de Tukey a $5 \%$ de probabilidade.

\section{Conclusões}

Considerando os resultados obtidos, concluiu-se que S-metolachlor $\left(1920 \mathrm{~g} \mathrm{ha}^{-1}\right.$, no plantio) seguido de s-metolachlor + ametryn $\left(1920+1500 \mathrm{~g} \mathrm{ha}^{-1}\right.$, após o quebra-lombo) foi eficaz no controle de $B$. decumbens e $M$. pudica, e seletivo em cana-planta variedade RB 92579.

S-metolachlor (1920 $\mathrm{g} \mathrm{ha}^{-1}$, no plantio) seguido de s-metolachlor + hexazinone+diuron $\left(1920+900 \mathrm{~g} \mathrm{ha}^{-1}\right.$, após o quebra-lombo $)$ foi eficaz no controle de $B$. decumbens e seletivo em cana-planta variedade RB 92579. Smetolachlor + ametryn $\left(960+750 \mathrm{~g} \mathrm{ha}^{-1}\right.$, no plantio) seguido de s-metolachlor + ametryn $\left(960+1500 \mathrm{~g} \mathrm{ha}^{-1}\right.$, após o quebra-lombo) foi eficaz no controle de $M$. pudica e seletivo em cana-planta variedade RB 92579.

S-metolachlor (1920 $\mathrm{g} \mathrm{ha}^{-1}$, no plantio) seguido de s-metolachlor + amicarbazone (1920 $+1050 \mathrm{~g} \mathrm{ha}^{-1}$, após o quebra-lombo) foi altamente eficaz no controle de $B$. decumbens e M. pudica.

\section{Referências}

CARVALHO, F.T. Influência das características do sulco de plantio de canade-açúcar (Saccharum spp. L.) na uniformidade de deposição da pulverização de herbicidas em pré-emergência. Botucatu: UNESP-FCA, 1999. 68 p. Tese (Doutorado em Agronomia) - Faculdade de Ciências 
Agronômicas, Universidade Estadual Paulista, 1999.

CHRISTOFFOLETI, P.J. Manejo das plantas daninhas na cultura da cana-de-açúcar. In: IV SIMPÓSIO DE TECNOLOGIA DE PRODUÇÃO DE CANA-DE-AÇÚCAR. Piracicaba, 2009. Disponível $<$ http://wwwgape.esalq.usp.br/cana2009/painel 5/04-1.pdf>. Acesso em: 24/09/2009.

LORENZI, H. et al. Manual de identificação e controle de plantas daninhas: plantio direto e convencional. $6^{\mathrm{a}}$ Ed., Nova Odessa, SP: Plantarum, 2006. 339p.

MACIEL, C.D.G. et al. Eficiência e seletividade dos herbicidas trifloxysulfuronsodium + ametryne e hexazinone + diuron em função da tecnologia de aplicação e do manejo mecânico da palha de cana-de-açúcar na linha de plantio. Planta Daninha, v.26, n.3, p.665676, 2008.

PITELLI, R.A.; KUVA, M.A. Dinâmica de populações de plantas daninhas e manejo da resistência aos herbicidas e seleção de flora. In: Curso de Recomendações Básicas de Manejo de Plantas Daninhas e Resistência aos Herbicidas. Piracicaba: Escola Superior de Agricultura "Luiz de Queiroz", 1998. p.1-46.

RODRIGUES, B.N.; ALMEIDA, F.S. Guia de herbicidas. $5^{\text {a }}$ ed., Londrina: Edição dos Autores, 2005. 592p.

SBCPD. Procedimentos para instalação, avaliação e análise de experimentos com herbicidas. Londrina: SBCPD, 1995, 42p.

SILVEIRA, G.M. O preparo do solo: implementos corretos. $3^{\mathrm{a}}$ Ed., São Paulo: Globo, 1989. 243p.

TOLEDO, R.E.B. et al. Eficácia do herbicida amicarbazone aplicado sobre a palha ou no solo no controle de plantas daninhas na cultura da cana-de-açúcar. Planta Daninha, v.27, n.2, p.319-326, 2009. 